\title{
POROSITY OF SEDIMENT MIXTURES WITH DIFFERENT TYPE OF GRAIN SIZE DISTRIBUTION
}

\author{
Muhammad SULAIMAN ${ }^{1}$, Daizo TSUTSUMI ${ }^{2}$ and Masaharu FUJITA ${ }^{3}$ \\ ${ }^{1}$ Student member of JSCE, Graduate Student, Dept. of Civil and Earth Resources Eng., Kyoto University \\ (Yoshida-Honmachi, Sakyo-ku, Kyoto 606-8501, Japan) \\ 2 Member of JSCE, Dr. Agr., Assistant Professor, Disaster Prevention Research Institute, Kyoto University \\ (Gokasho, Uji 611-0011, Japan) \\ ${ }^{3}$ Member of JSCE, Dr. Eng., Professor, Disaster Prevention Research Institute, Kyoto University \\ (Gokasho, Uji 611-0011, Japan)
}

\begin{abstract}
Assessing the change in void structure of riverbed material is very important for an ecological issue in rivers. Therefore, we have already developed a framework of the bed variation model available for the analysis of the change of porosity of bed material as well as the bed variation. In this framework, the porosity is assumed to be dependent only on the grain size distribution. Thus, it is necessary to relate the porosity of sediment mixture with the grain size distribution in the model. This study aims to develop a method for obtaining the porosity for different types of grain size distribution. Firstly, grain size distribution of sediment mixture in natural rivers were classified into three types, namely log-normal distribution, Talbot distribution and bimodal distribution, and the parameters on those geometric properties were found out. Secondly, a method for identifying the type of grain size distribution was presented. Thirdly, the relationship between the porosity and the geometric parameter of grain size distribution was obtained by means of a packing model. Finally, the porosity of actual riverbed material was estimated by the presented method. The porosity could be reasonably estimated by means of the presented method and it could be introduced into the bed variation model.
\end{abstract}

Key Words: sediment mixture, porosity, grain size distribution, bed material, bed variation model

\section{INTRODUCTION}

Among the qualitative features of bed material, the grain size distribution and the porosity are very important properties governing a habitat condition of aquatic living things. Particularly, many ecologists are interested in the void structure of the bed material ${ }^{1)}$. The effects of porosity changes from sedimentation on the riverbed environment have been widely investigated ${ }^{2,3}$. For a situation where the fine sand is supplied to the riverbed with armor coat, the previous bed variation models are available for the analysis of bed variation and the change in grain size distribution. However, they cannot provide any result on the change in porosity. They are, therefore, incomplete for assessing the qualitative change of bed material from an ecological point of view. Fujita et al. ${ }^{4)}$ have presented a framework of riverbed variation model to simulate the change of porosity as well as bed variation. For a sediment mixture of particles with two much different grain sizes, a simple analytical model has been already presented under this framework. However, it cannot be used for general grain size distribution. The porosity of sediment mixtures depends on the grain size distribution ${ }^{5), 6)}$. If the porosity is related to the grain size distribution, the simple model could be improved in applying to general cases.

Actual sediment mixtures have various types of grain size distribution. Therefore, it is necessary to obtain the porosity for each grain size distribution one by one in calculation of bed variation. However, it is not practical. It is better to install some relationships between porosity and typical grain size distribution in the bed variation model in advance. For that modeling, classification and identification of the grain size distribution type are necessary. 
This study aims to develop a method for identifying the type of grain size distribution and obtaining the porosity for the different type of grain size distribution. Firstly, grain size distribution of sediment mixture in natural rivers were classified into three types, namely log-normal distribution, Talbot distribution and bimodal distribution, and the parameters on those geometric properties were found out. Secondly, a method for identifying the type of grain size distribution was presented. Thirdly, the relationship between the porosity and the geometric parameter of grain size distribution was obtained by means of a packing model developed by Tsutsumi et al. ${ }^{6}$. Finally, the porosity of actual riverbed material was estimated by the presented method.

\section{CLASSIFICATION}

\section{(1) Data}

Riverbed materials have a variety of different characteristic size of bed surface sediment ${ }^{7)}$, but the grain size distribution could be classified into some types. One of the most typical density functions of grain size is a log-normal distribution. The grain size distribution of bed material in most sand-bed streams is unimodal and that in many gravel-bed rivers is bimodal ${ }^{8}$. Also in mountainous rivers, the surface bed material has usually Talbot distribution of grain size ${ }^{9)}$.
The grain size distribution of natural riverbed material and produced sediment were collected for analysis of classification and identification of grain size distribution. The samples were taken from Ai River ${ }^{10)}$, Hino River ${ }^{11)}$, Ohtaki River ${ }^{12)}$ and Fukadani bare slope. The grain size distributions $f$ and those density functions $p$ are shown in Figures 1 and 2 . The sampling points are summarized in Table 1 . Capital letter $\mathrm{A}, \mathrm{H}, \mathrm{O}$ and $\mathrm{F}$ denote the samples from Ai River, Hino River, Ohtaki River and a Fukadani bare slope, respectively. The samples were classified by the characteristics of sampling points as follows:

(a) Surface bed material (A-1, 5, H-1, 2, 3)

(b) Sub-surface bed material (A-2, 6, H-4, 5, 6)

(c) Sand bar (A-3)

(d) Sediment deposition in a sabo dam (A-4)

(e) Sediment deposition in a valley immediately after Ontake Lanslide 1984 (O-1)

(f) Sediment deposition in a reservoir $(\mathrm{O}-2,3)$

(g) Sediment produced at a bare slope $(\mathrm{F}-1,2,3)$

\section{(2) Typical grain size distribution}

The grain size distributions shown in Figure 1 are roughly classified into three types of grain size distribution, namely, log-normal distribution, Talbot distribution and bimodal distribution. Typical of the grain size distributions of sediment mixture are shown in Figure 3, where $f$ is the percentage of the finer grain size and $p(=d f / d(\log d))$ is the density function of grain size.

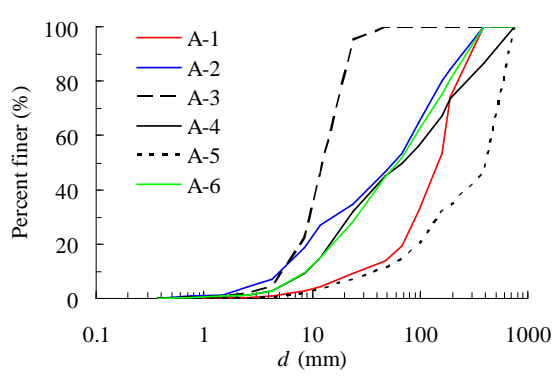

a) Ai River

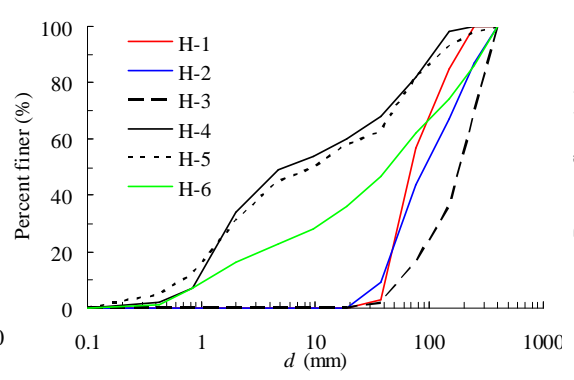

b) Hino River

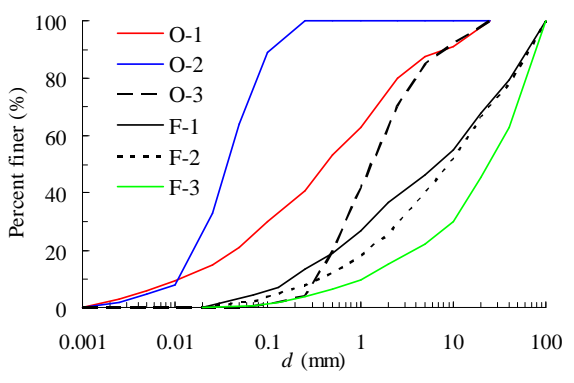

c) Ohtaki River and Fukadani

Fig. 1 Grain size distributions of bed material and produced sediment
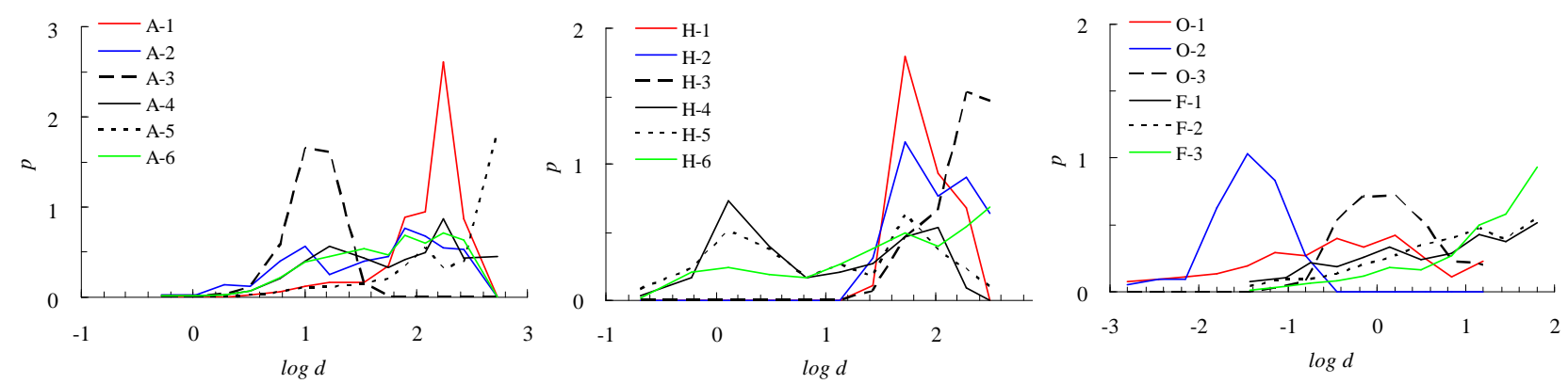

Fig. 2 Density distributions of grain size distribution shown in Fig.1 
Table 1 Parameters of actual grain size distribution

\begin{tabular}{|c|c|c|c|c|c|c|c|c|c|}
\hline No. & Sample sites & $\begin{array}{l}\mathrm{d}_{\min } \\
(\mathrm{mm})\end{array}$ & $\begin{array}{l}\mathrm{d}_{50} \\
(\mathrm{~mm})\end{array}$ & $\begin{array}{c}\mathrm{d}_{\text {peak }} \\
(\mathrm{mm})\end{array}$ & $\begin{array}{c}\mathrm{d}_{\max } \\
(\mathrm{mm})\end{array}$ & $\bar{\beta}$ & $\gamma$ & $\mathrm{n}_{\mathrm{p}}$ & Type \\
\hline A-1 & Surface bed in upstream of Gokuraku Bridge in Ai River & 0.740 & 149.23 & 159.00 & 381.00 & 0.14 & 0.15 & 1 & $T$ \\
\hline A-2 & Sub-surface bed in upstream of Gokuraku Bridge in Ai River & 0.370 & 57.70 & 67.80 & 381.00 & 0.25 & 0.27 & 2 & B \\
\hline A-3 & Sand bar in downsream of Gokuraku Bridge in Ai River & 0.370 & 12.77 & 8.50 & 47.60 & 0.35 & 0.27 & 1 & L \\
\hline A-4 & Deposit in Ai gawa sabo dam in Ai River & 0.370 & 67.80 & 159.00 & 750.00 & 0.20 & 0.32 & 2 & B \\
\hline A-5 & Surface bed near Kurumatukuri Bridge in Ai river & 2.500 & 409.49 & 381.00 & 750.00 & 0.00 & 0.11 & 1 & $\mathrm{~T}$ \\
\hline A-6 & Sub-surface bed in Kurumatukuri Bridge in Ai river & 0.370 & 62.75 & 159.00 & 381.00 & 0.13 & 0.26 & 1 & $\mathrm{~T}$ \\
\hline $\mathrm{H}-1$ & Surface bed in the upstream of river mouth of Hino River & 19.000 & 70.14 & 37.50 & 250.00 & 0.74 & 0.49 & 1 & AT \\
\hline $\mathrm{H}-2$ & Surface bed in Lower Hino River & 19.000 & 94.57 & 37.50 & 400.00 & 0.78 & 0.47 & 1 & AT \\
\hline $\mathrm{H}-3$ & Surface bed in Middle Hino River & 19.000 & 191.18 & 150.00 & 400.00 & 0.32 & 0.24 & 1 & $\mathrm{~T}$ \\
\hline $\mathrm{H}-4$ & Sub-surface bed in the upstream of river mouth of Hino River & 0.100 & 5.70 & 0.85 & 250.00 & 0.73 & 0.48 & 2 & B \\
\hline $\mathrm{H}-5$ & Sub-surface bed in Lower Hino River & 0.100 & 9.50 & 37.50 & 400.00 & 0.29 & 0.45 & 2 & B \\
\hline H-6 & Sub-surface bed in Middle Hino River & 0.100 & 45.00 & 250.00 & 400.00 & 0.00 & 0.26 & 1 & $\mathrm{~T}$ \\
\hline O-1 & Deposit in Ohtaki River immediately after Ontake Landslide, 1984 & 0.001 & 0.44 & 1.00 & 25.00 & 0.32 & 0.40 & 1 & $\mathrm{~T}$ \\
\hline $\mathrm{O}-2$ & Deposit of wash load in Makio Reservoir & 0.001 & 0.03 & 0.03 & 0.25 & 0.42 & 0.38 & 1 & L \\
\hline $\mathrm{O}-3$ & Deposit of bed material load in Makio Reservoir & 0.050 & 1.45 & 1.00 & 25.00 & 0.52 & 0.46 & 1 & L \\
\hline F-1 & Sediment produced at Fukadani bare slope on May 28,2002 & 0.020 & 7.08 & 40.00 & 100.00 & 0.00 & 0.31 & 1 & $\mathrm{~T}$ \\
\hline $\mathrm{F}-2$ & Sediment produced at Fukadani bare slope on July 1,2002 & 0.020 & 9.29 & 40.00 & 100.00 & 0.00 & 0.28 & 1 & $\mathrm{~T}$ \\
\hline $\mathrm{F}-3$ & Sediment produced at Fukadani bare slope on November 12,2002 & 0.020 & 25.49 & 40.00 & 100.00 & 0.00 & 0.16 & 1 & $\mathrm{~T}$ \\
\hline
\end{tabular}

L: Log-normal distribution; T: Talbot distribution; B: Bimodal distribution ; AT: Anti-Talbot distribution

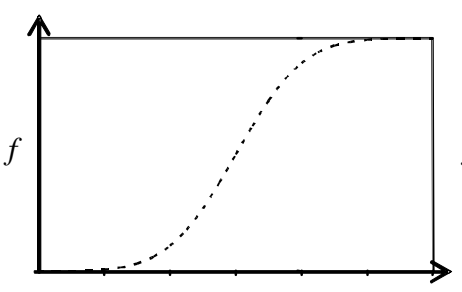

d

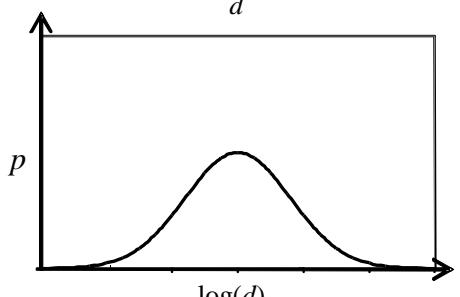

(a) Log-normal type

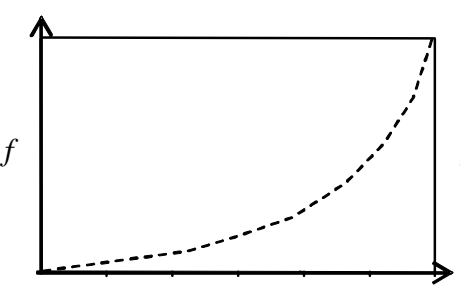

$d$

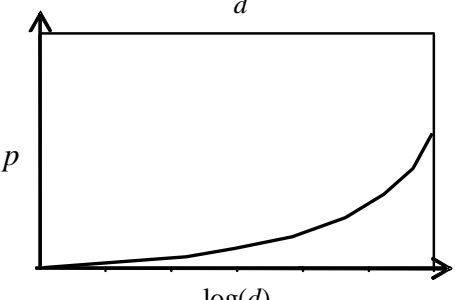

(b) Talbot type

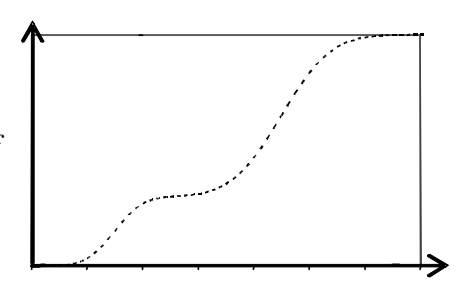

d

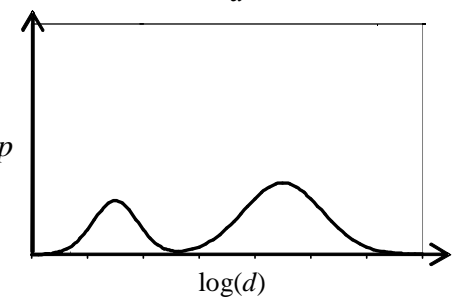

(c) Bimodal type

Fig.3 Typical of grain size distribution of sediment mixture and the density function of grain size

(a) Log-nor mal distribution

Log-normal grain size distribution is shown in Figure 3 (a). The density function is as follows:

$$
p(\ln d)=\frac{1}{\sqrt{2 \pi} \sigma_{\mathrm{L}}} \exp \left[-\frac{\left(\ln \mathrm{d}-\ln \mathrm{d}_{\mathrm{mg}}\right)^{2}}{2\left(\sigma_{\mathrm{L}}\right)^{2}}\right]
$$

where $d_{m g}=$ the geometric average of grain size and $\sigma_{L}=$ standard deviation of lnd. Normalizing $d$ with $d_{\mathrm{mg}}, \sigma_{L}$ is only a parameter of the log-normal distribution. The porosity of the mixture is, therefore, dependent on $\sigma_{L}$.

\section{(b) Talbot distribution}

It is well known that the surface bed material of mountainous rivers has Talbot type of grain size distribution shown in Figure 3(b). The grain size distribution function is as follows:

$$
f(d)=\left(\frac{d}{d_{\max }}\right)^{n}
$$

where $d_{\max }$ is the maximum grain size and $n$ is a coefficient.

Figure 4 shows the result of fitting A-1 and F-1 with Eq.(2). The narrow distribution can be expressed by Eq.(2), but the difference is much larger for the finer size of the wide distribution. This result indicates that the minimum grain size as well as the maximum size should be introduced into the distribution as a parameter. Therefore, Eq.(3) is defined as a similar distribution with Talbot distribution. The porosity of the mixture is determined with Talbot number, $n_{T}\left(n_{T}>1\right)$, and $\mathrm{d}_{\max } / \mathrm{d}_{\min }$. 


$$
f(d)=\left(\frac{\log d-\log d_{\text {min }}}{\log d_{\text {max }}-\log d_{\text {min }}}\right)^{n_{T}} ; n_{T}>1
$$

\section{(c) Bimodal distribution}

A grain size distribution is said to be bimodal if the density distribution $p(d)$, displays two distinct peaks. Each peak is a mode of a portion of the distribution. The grain size distribution shown in Figure 3 (c) is the bimodal distribution composed of two log-normal distributions with different mean size and standard deviation. When the geometric averages of grain size are $d_{m g A}$ and $d_{m g B}$, the standard deviation are $\sigma_{\mathrm{A}}$ and $\sigma_{\mathrm{L}}$, the mixing ratio are $\mathrm{p}_{\mathrm{A}}$ and $p_{B}\left(=1-p_{A}\right)$, the parameters governing porosity are $\sigma_{L A}, \sigma_{L B}, d_{m g A} / d_{m g B}$ and $p_{A}$.

\section{(3) I dentification and classification}

The grain size distributions of natural sediment mixture can be identified and classified visually based on the shape of size distribution and density distribution. The grain size distribution classified into log-normal distribution if the trend of the size distribution curves similar to log-normal curve and the density distribution has a single peak. If the density distribution is skewed towards a high-end tail of distribution, the grain size distribution is classified into Talbot distribution. If the density distribution has two peaks, the grain size distribution classified into bimodal distribution.

As shown in Figure 3, the shapes of density function $p$ are quite different from each other. Therefore, the type of grain size distribution can be identified if an index expressing the shape of density function $p$ found out. Figure 3 shows the number of peak of density function for bimodal distribution is two. It is easy to understand that the number of peak, $n_{p}$, is an index for determine of unimodal or bimodal distribution. A-2, A-4, H-4 and H-5 are therefore, identified as bimodal distribution.

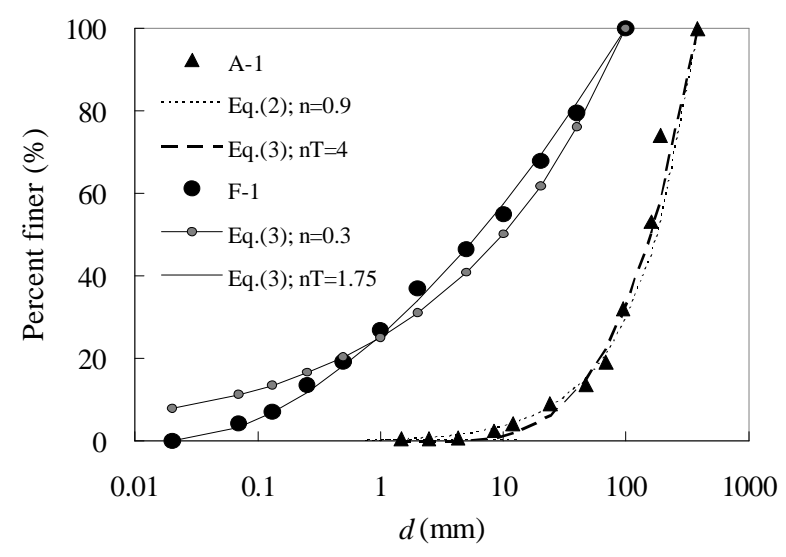

Fig.4 Fitting curve for Talbot distribution
In addition, the following two indices are taken:

$$
\beta=\frac{\log d_{\text {max }}-\log d_{\text {peak }}}{\log d_{\text {max }}-\log d_{\text {min }}} ; \gamma=\frac{\log d_{\text {max }}-\log d_{50}}{\log d_{\text {max }}-\log d_{\text {min }}}
$$

where $d_{\min }$ is minimum size, $d_{50}$ is $50 \%$ size, $d_{\max }$ is maximum size, and $d_{\text {peak }}$ is a diameter which give maximum value of $p$. These indices designate the relative locations of $d_{50}$ and $d_{\text {peak }}$ between $d_{\text {min }}$ and $\mathrm{d}_{\max } . \beta$ and $\gamma$ are 0.5 for log-normal distribution and 0.0 for Talbot distribution. Actually, the critical value of these indices should be determined for each type.

A type of the distribution can be determined by the shape of size distribution, the shape of density distribution, and values of $\beta$ and $\gamma$. The values of $\beta$ and $\gamma$ are listed in Table 1. Figure 5 shows the relation between $\beta$ and $\gamma$. A-1, A-5, A-6, H-6, F-1, F-2 and F-3 plotted with filled circles are visually identified as Talbot distribution. H-3 and O-1 plotted with triangles are visually identified the distribution between Talbot and log-normal. A-3, O-2, O-3 plotted with open circles are visually identified as log-normal distribution. $\mathrm{H}-1$ and $\mathrm{H}-2$ plotted with cross are the distribution between log-normal and anti-Talbot. Anti-Talbot distribution is defined by Eq. (3) with value of Talbot number, $n_{T}$, less than $1\left(n_{T}<1\right)$.

Based on the visual identification and the relation between $\beta$ and $\gamma$, the critical value of these indices for each type distribution can be determined. The critical values of the indices were determined by adding and reducing the value of $\beta$ and $\gamma$ for log-normal distribution (0.5) with certain value $\alpha$. According to the relation between $\beta$ and $\gamma$ as shown in Figure 5, the value of $\alpha= \pm 0.2$ is reasonable. Grain size distributions are classified into Talbot type if $\beta \leq 0.3$ and $\gamma \leq 0.3$, log-normal type if $0.3<\beta<0.7$ and $0.3<\gamma<0.7$ and anti-Talbot type if $\beta>0.7$ and $\gamma>0.7$.

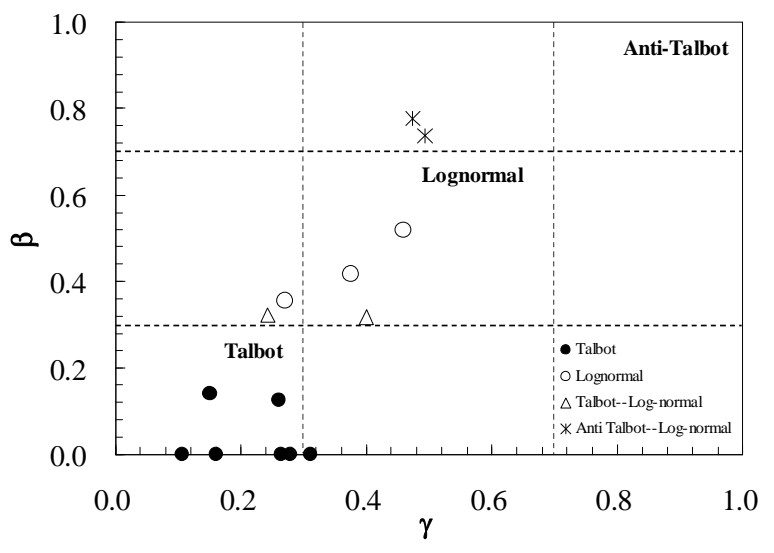

Fig.5 Relation between $\beta$ and $\gamma$ 


\section{RELATIONSHIP BETWEEN GRAIN SIZE DISTRIBUTION AND POROSITY}

Tsutsumi et al. ${ }^{6}$ ) have developed a particlepacking model generating the porosity of a sediment mixture. The validity of the model was assessed with a laboratory experiment, in which six different-sized spherical glass beads were prepared and mixed well to form six different kinds of particle size distribution. The model results showed that the porosity is associated with the grain size distribution.

\section{(1) L og-normal distribution}

Porosity whose grain size distribution of the materials is log-normal distribution with a standard deviation of 0 to 1.5 was calculated by means of the packing model. A relationship between the standard deviation $\sigma$ and the calculated porosity is shown in Figure $6^{6}$. If the standard deviation $\sigma$ is between 0.01 and 0.1 , the porosity is about 0.38 . This value is close to the value (0.4) generally used in conventional calculations on riverbed variation. The porosity decreases to 0.156 when the standard deviation $\sigma_{\mathrm{L}}$ increases to 1.50 . When the particle size is widely distributed, the porosity takes much smaller value than 0.4 . The porosity increased drastically from 0.33 to 0.38 when the standard deviation $\sigma$ increase slightly from 0.0 to 0.1 . This means that the porosity increases drastically if particles with a different size are put into a uniform material.

\section{(2) Talbot distribution}

Porosity of the material whose grain size distribution is Talbot distribution with the varies value of Talbot number, $n_{T}$, was calculated by means of the packing model. Ratio of maximum and minimum size $\left(d_{\max } / d_{\min }\right)$ are 10 and 100. A relationship between the value of Talbot number, $n_{T}$, and the calculated porosity is shown in Figure 7. The porosity increased from 0.241 to 0.314 for $\mathrm{d}_{\max } / \mathrm{d}_{\min }=10$ when the Talbot number, $\mathrm{n}_{\mathrm{T}}$, increased from 2 to 8 . The porosity increased from 0.173 to 0.273 for $d_{\max } / d_{\min }=100$ when the Talbot number, $n_{T}$, increased from 4 to 12 . Smaller ratio of $d_{\max } / d_{\min }$ gives the higher value of porosity.

\section{(3) Bimodal distribution}

Generally, bimodal distribution ranges widely. A simulation of its porosity by means of packing model needs much time. Considering the simulation time, in this study the artificial bimodal distributions with narrow distribution were used. The characteristic of materials are shown in Table 2. Porosities for seven different fine proportions $p_{A}$ (i.e., $0,0.2,0.25,0.3,0.5,0.75$ and 1) were estimated. Relationship between fine proportion $p_{A}$ (by volume) of mixture and the porosity for two fraction mixture are shown in Figure 8. The porosity of two component mixtures depends on the fractional concentrations of each particle size population. The results were compared with the porosity of two-particle mixture presented by Fujita ${ }^{10)}$. Interestingly, the change of porosity for two particles mixture and two fractions mixture is similar and a porosity minimum is observed.

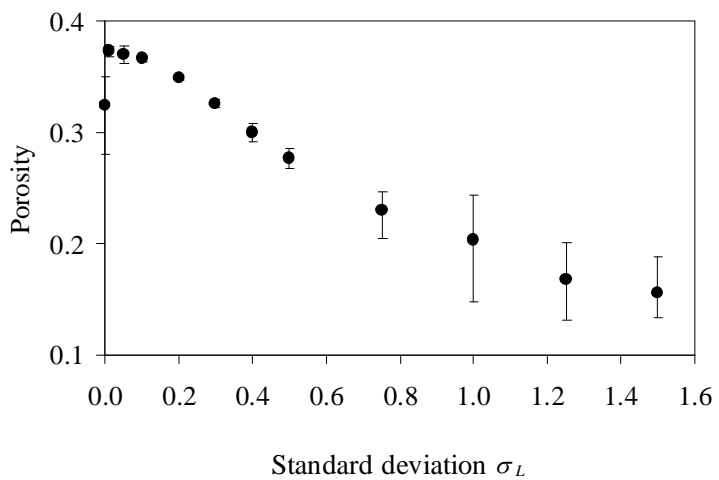

Fig. 6 Relationship between the standard deviation, $\sigma$, and the porosity (after Tsutsumi et al. ${ }^{6}$ )

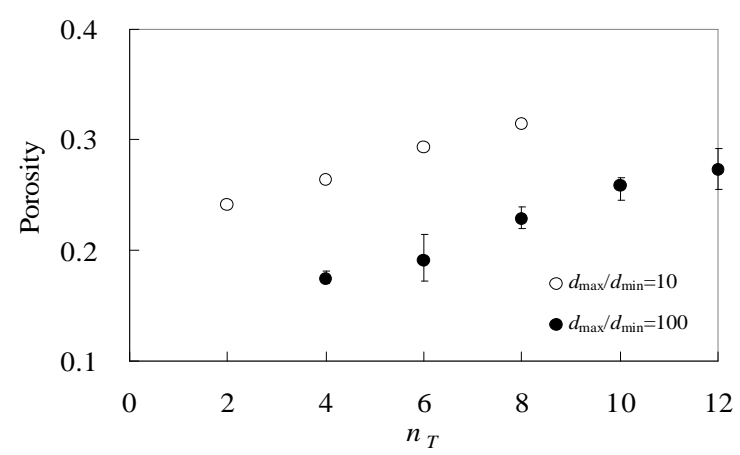

Fig. 7 Relationship between the Talbot number, $n_{T}$, and the porosity

Table 2 Characteristic of sediment for bimodal distribution

\begin{tabular}{ccccc}
\hline Fraction & $\sigma$ & $\begin{array}{c}\mathrm{d}_{\min } \\
(\mathrm{mm})\end{array}$ & $\begin{array}{c}\mathrm{d}_{50} \\
(\mathrm{~mm})\end{array}$ & $\begin{array}{c}\mathrm{d}_{\max } \\
(\mathrm{mm})\end{array}$ \\
\hline A & 0.2 & 0.5 & 1.0 & 2.0 \\
B & 0.2 & 2.0 & 4.0 & 8.0 \\
\hline
\end{tabular}

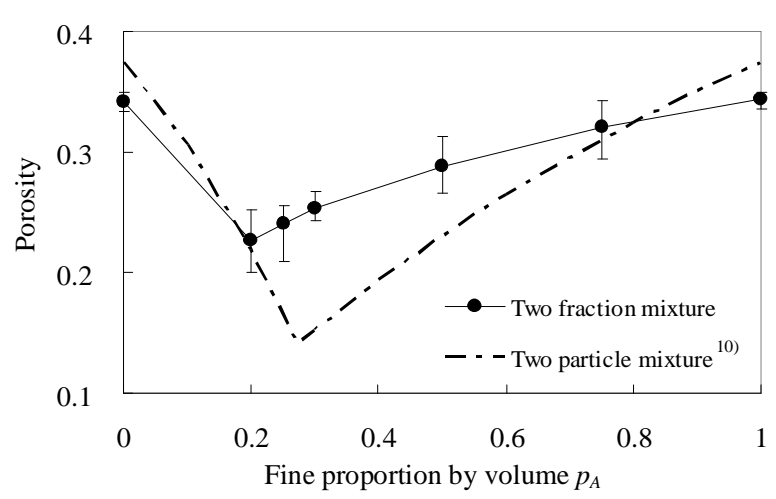

Fig. 8 Relationship between the fine proportion of mixture and porosity 


\section{APPLICATION}

The presented method and results in the previous section are applied to estimate the porosity of actual riverbed material. Three different types of actual grain size distribution that represent the log-normal distribution (A-3 and $\mathrm{H}-1$ ) and Talbot distribution (A-5) were selected. The standard deviation for A-3 and $\mathrm{H}-1$ were determined from the data of grain size distribution and the distribution curves were drew (Figure 9). Talbot number for A-5 was determined by means of fitting curve defines by Eq.(3) (Figure 9). Then, the porosity of each grain size distribution was determined by using the diagram of relationship between the geometric parameter of grain size distribution and the porosity (Figure 6 and 7). The porosities obtained from the diagram were compared with the porosity estimated by using packing model.

The standard deviation of A-3 and H-1 obtained from the data are 0.60 and 0.52 . Talbot number of A-5 is 4 . The porosity of A-3, H-1 and A-5 obtained from the diagram are $0.25,0.27$ and 0.19 respectively. The porosity of A-3, H-1 and A-5 obtained from packing model simulation are $0.23,0.29$ and 0.22 respectively. The discrepancy of porosity for lognormal distribution may be due to the distribution of actual grain sizes are not symmetric, while the assumption using a log-normal type of equation is that the grain size distribution is symmetric. In the case of Talbot distribution, the discrepancy of porosity may be due to the grain size distribution was dominated by large particles.

\section{CONCLUSIONS}

A method for obtaining the porosity for different types of grain size distribution was developed. The results are as follows:

(1) Grain size distribution of actual sediment mixture can be roughly classified into three types of distribution, namely, log-normal distribution, Talbot distribution and bimodal distribution, based on the mode of density distribution and indices $\beta$ and $\gamma$. However, to determine the exact distribution type, we need to find out another index.

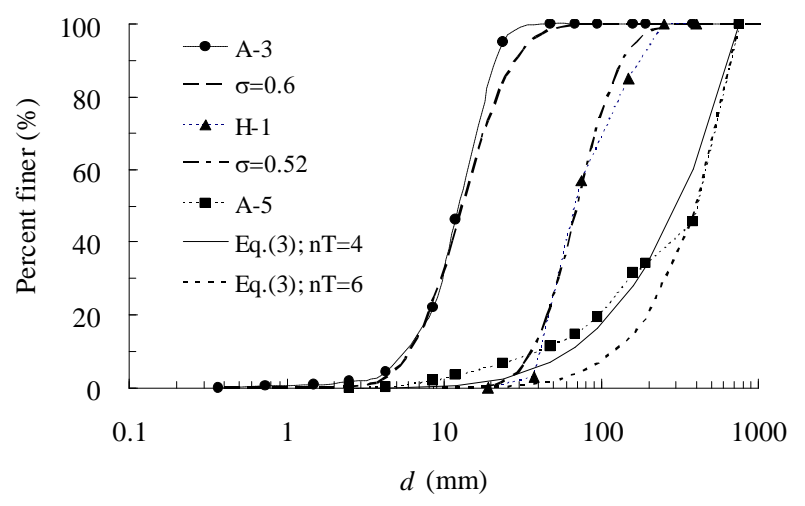

Fig. 9 Fitting curve for log-normal and Talbot distribution
(2) Relationship between the grain size distribution and the porosity can be determined by using the geometric properties of grain size distribution. The porosity of log-normal distributions decreased with an increasing standard deviation. The porosity of Talbot distributions increased with an increasing of the Talbot number $n_{T}$ and smaller ratio of $d_{\max } / d_{\min }$ gives the higher value of porosity. The porosity of bimodal distribution depends on the percentage of each fraction in the mixture. In case of the mixture of two fraction under the condition shown in Table 2, the minimum porosity was found if the percentage of finer fraction is 0.20 .

(3) The porosity could be reasonably estimated by means of the presented method and it could be introduced into the bed variation model.

Although the simulation method was assessed by the laboratory experiment with the glass beads, however, it is not known whether these results represent the void properties of natural riverbed materials. Further assessment of the method with the porosity of natural riverbed materials is required.

\section{REFERENCES}

1) Gayraud, S., Philippe, M.: Influence of bed-sediment features on the interstitial habitat available for macroinvertebrates in 15 French streams, Internat. Rev. Hydrobiol., Vol. 88, pp. 77-93, 2003.

2) ASCE Task Committee on Sediment Transport and Aquatic Habitats: Sediment and aquatic habitat in rivers systems, Journal of Hydraulics Eng., Vol. 118, pp. 669-687, 1992.

3) Milhous, R.T.: Effect of sediment transport and flow regulation on the ecology of gravel-bed rivers. Gravel-bed Rivers, Hey, R.D., Bathurst, J.C. and Thorne, C.R., eds., John Wiley \& Sons, pp. 819-842, 1982.

4) Fujita, M., Tsutsumi, D., and Sulaiman, M.: A simulation method for quantitative and qualitative changes of riverbed, Proc. of International Conference on Fluvial and Coastal Disasters, CD-ROM, 2005.

5) Standish, N. and Borger, D.E.: The porosity of particulate mixtures, Powder Technology, Vol 22, pp. 121-125, 1979.

6) Tsutsumi, D., Fujita, M., and Sulaiman, M.: Changes in the void ratio and void structure of riverbed material with particle size distribution. River, Coastal and Estuarine M orphodynamics, Vol. 2, Parker, G., Garcia, M.H., eds., Taylor \& Francis, pp. 1059-1065, 2006.

7) Bunte, K. and Abt, S.R.: Sampling surface and subsurface particle-size distribution in wadable gravel- and cobble-bed streams for analyses in sediment transport, hydraulics, and streambed monitoring, 428 p., Rocky Mountain Station, USDA, 2001.

8) Parker, G.: 1D Sediment transport morphodynamics with applications to rivers and turbidity current, e-book, 2004, http://cee.uiuc.edu/people/parkerg/morphodynamics_e-book.htm

9) Tatsuzawa, H., Hayashi, H. and Hasegawa, K.: Roles of heterogeneous property of bed materials for the formation of steep-pool system in mountain streams, Annual J ournal of Hydraulic Engineering, J SCE, Vol. 42, pp. 1075-1080, 1998 (in Japanese).

10) Fujita, M.: Study on riverbed morphology as habitat for aquatic living things, Report, River Environment Fund, Foundation of River Watershed Environment Management, 2004 (in Japanese).

11) Hinogawa River Office of MLIT: Technical Report on Integrated Sediment Management of Hino River Basin 2003, 2004 (in Japanese).

12) Ashida, K. and Fujita, M.: Simulation of reservoir sedimentation, Annuals, DPRI, Kyoto U niversity, No. 30 B-2, 1987 (in Japanese).

(Received September 30, 2006) 